\title{
Recent Trends of Coated Sheet Steels for Automotive use
}

\author{
Man-Been Moon $^{\dagger}$ \\ Hyundai HYSCO, 313, Donggok-ri, Songsan-myeon, Dangjin-gun, Chungnam-do, Korea \\ (Received October 20, 2009; Revised April 12, 2012; Accepted April 13, 2012)
}

\begin{abstract}
Recent issues in the automotive industries are, improvement of fuel efficiency according to the worldwide $\mathrm{CO}_{2}$ regulation, passenger safety through enhanced crashworthiness, superior design and cost reduction due to price fluctuation of raw material. To meet these demands, steelmaking companies are developing advanced high strength steel and new process technologies such as hydroforming, TWB(Tailor Welded Blank), hot stamping and so on. In addition, eco-friendly and high corrosion resistant coating technologies are getting more attention to comply with the environmental regulations. In this paper, reviews and prospects of recent coating technologies for automotive use are presented.
\end{abstract}

Keywords : automotive steel, galvanized, high strength steel, lightweight technology

\section{Application trends of automotive sheet steels}

The needs for the lightweight automotive body resulted in the development of advanced high strength steels. Worldwide carmakers are competitively applying these high strength steels more than ever to save carbody weight and to increase fuel efficiency.

Fig. 1 shows the long term plan for automotive steel application in Hyundai-Kia Motor Company. Application of $340 \mathrm{MPa}$ and $440 \mathrm{MPa}$ grade are declining sharply, whereas steel grades above $590 \mathrm{MPa}$ are growing up to $48 \%$ in order to achieve lightweight automotive body. In particular, 1180 1470 MPa grade structural reinforcement parts are gradually increasing.

Environmental conditions of the automobiles are getting more severe due to the pollutions, acid rain and the deicing

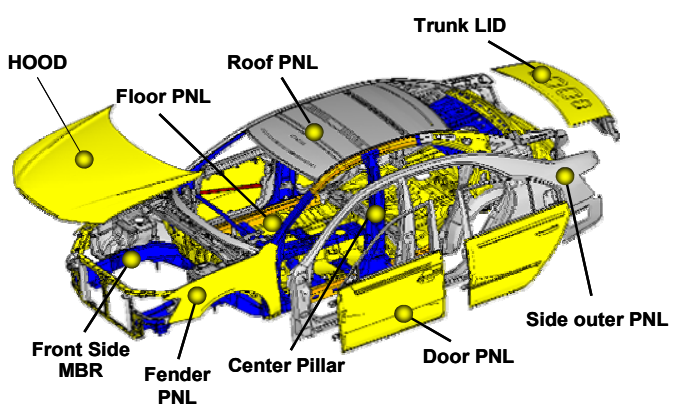

\begin{tabular}{|c|c|c|c|}
\hline \multicolumn{2}{|c|}{ Parts } & 2008 & 2015 \\
\hline \multicolumn{2}{|c|}{ Outer Panels } & $340 \mathrm{MPa}$ & $590 \mathrm{MPa} \sim$ \\
\hline \multirow{3}{*}{ Structural } & Member & $340 \sim 590$ & $590 \sim 1180$ \\
\cline { 2 - 4 } & Reinforcement & $340 \sim 980$ & $590 \sim 2 \mathrm{GPa}$ \\
\hline \multicolumn{2}{|c|}{ Chassis } & $440 \sim 590$ & $590 \sim 1180$ \\
\hline
\end{tabular}

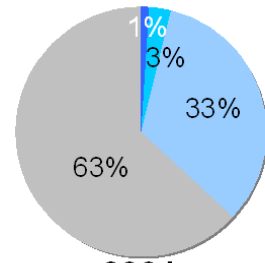

2001

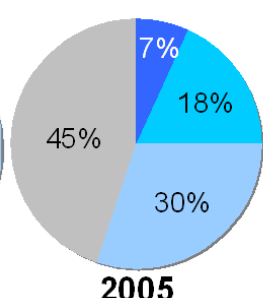

2005

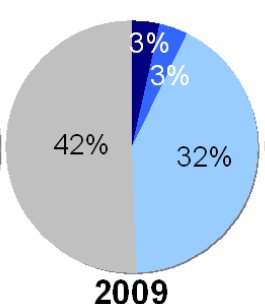

2009
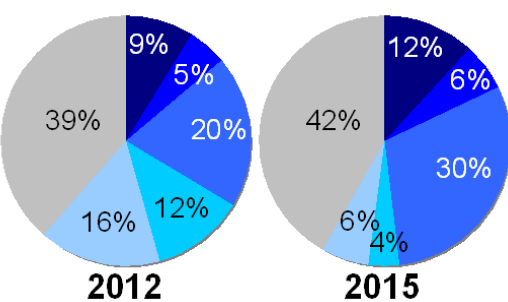

Fig. 1. Application trends of high strength steel in HKMC.

\footnotetext{
${ }^{\dagger}$ Corresponding author: mbmoon@hysco.com
} 
Table 1. Comosion warranty period of automobiles

\begin{tabular}{c|c|c|c}
\hline Corrosion Type & Canada `81 & Nordic `81 & N-America `90 \\
\hline Cosmetic & 1.5 & 3 & 5 \\
\hline Perforation & 5 & 6 & 10 \\
\hline Structural & 6 & 6 & 10 \\
\hline
\end{tabular}

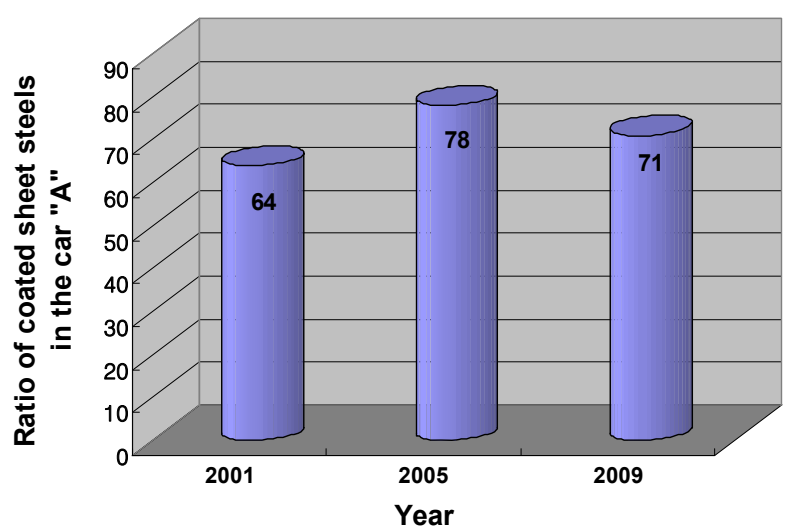

Fig. 2. The Ratio of coated sheet steels in the car "A", Hyundai Motors.

chemicals, and these conditions resulted in the corrosion problems. Corrosion warranty period has been constantly upgraded to maximize the service lifetime of the automobiles. Table 1 shows the various corrosion warranty period, and Fig. 2 shows the ratio of coated sheet steels in the car "A", Hyundai Motors.

\section{Development trends of automotive sheet steels}

Sheet steels for automotive use are of various kinds as shown in Fig. 3,9),10) and can be classified as ultra low carbon/low carbon steel, high strength steel and advanced high strength steel. Researches of high strength steel for lightening carbody and enhancing dent resistance are under progress. Solid solution hardening steels with up to 440 MPa of strength have been developed. BH(Bake Hardening) steels utilizing strain aging effect of solute carbon during baking process of a car have also been developed. Automotive parts for reinforcement and crash members require higher strength, and HSLA steels with precipitation hardening were used so far. However, as HSLA(High Strength Low Alloy) steels have limited formability and weldability, advanced high strength steels with transformation hardening such as DP(Dual Phase), TRIP(Transformation Induced Plasticity) and $\mathrm{CP}($ Complex Phase) have been being developed. More drastic formability enhancement can be acquired using extended ratio of austenite. TWIP (Twinning Induced Plasticity) steels with tensile strength

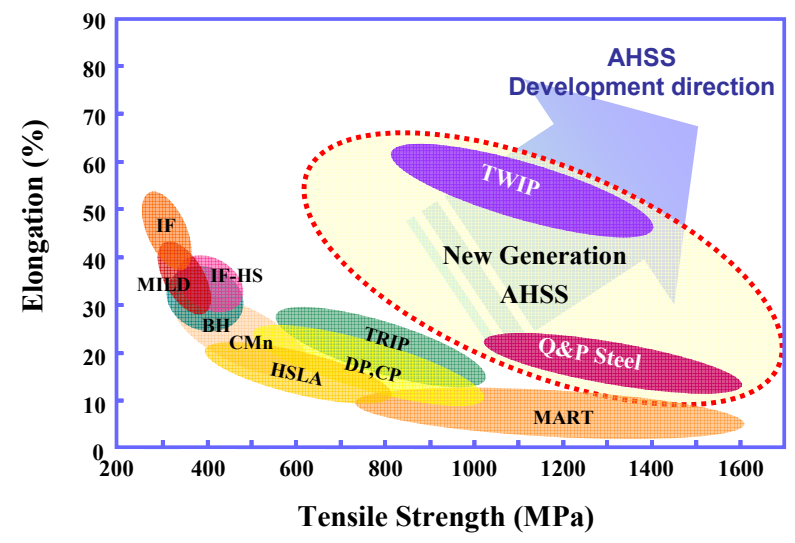

Fig. 3. Development status and trends of AHSS.

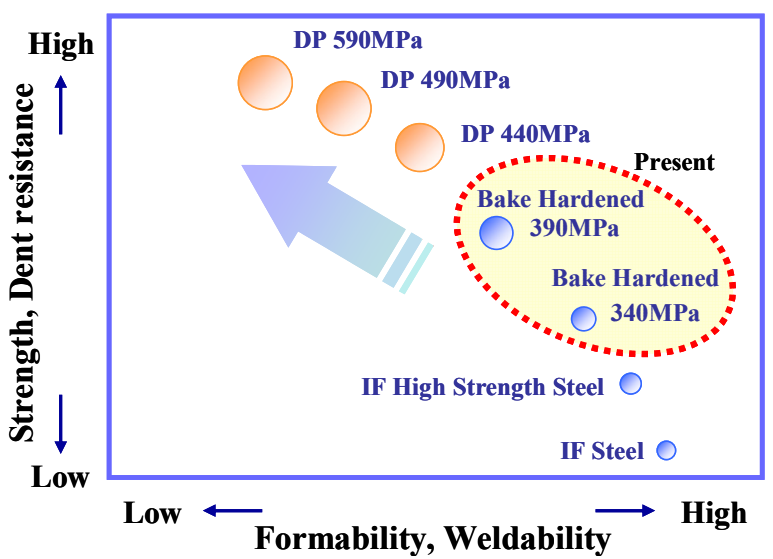

Fig. 4. Trends of automotive outer panel development.

of $800 \mathrm{MPa}$ and elongation of 50-90\% and Q\&P(Quenching \& Partitioning) steels with tensile strength of 1000 1500 $\mathrm{MPa}$ and elongation of $10 \sim 25 \%$ are kinds of these types. ${ }^{1,2), 3)}$ By applying these steels to the structural parts of automobile, lightened car body weight, improved fuel efficiency and enhanced crashworthiness are expected to be achieved.

\subsection{Outer panel development}

Fig. 4 shows the trends of automotive outer panels. Before 1990s, low carbon and aging free IF(interstitial free) steels were used as outer panels, and later, $340 \mathrm{MPa}$ IF steels were developed and applied. In early 1990s, dent resistance was taken greater attention, and accordingly 340 MPa BH steel was developed. After that, $490 \mathrm{MPa}$ DP steel with superior dent resistance and acceptable formability have been being developed and applied in some parts. ${ }^{8)}$ Furthermore, $590 \mathrm{MPa}$ dual phase steel for outer panel is also under developing by steelmaking companies. 


\subsection{Coating technology of high strength steel}

Typically, alloying elements such as silicon and manganese are included in the steel substrate to get higher strength and elongation. However, these alloying elements form oxides on the steel surface during annealing in the furnace atmosphere, resulting in the deterioration of wettability in molten zinc. In other words, silicon and manganese are preferentially oxidized and concentrated in the surface due to high affinity with oxygen, thus uncoated area can be generated(Fig. 5). To control the formation of such kinds of oxides, various researches are under progress. One of them is an oxidation-reduction process including formation of iron oxides in preheating section and reduction afterwards. ${ }^{4)}$ Another is electrolytic nickel plating prior to annealing and galvanizing. The third process is the internal oxidation method, which generates oxides beneath the metal surface in relatively higher oxidizing atmosphere. This method includes high temperature treatment in hot rolling process, resulting in generation of oxides in the grain boundaries and thus improving coating adhesion. ${ }^{5}$

\subsection{Environmental-friendly and advanced conosion resis- tant coating technology}

Coating technologies of high functional material on the steel substrate using cost effective vapor deposition techniques including PVD, CVD and PECVD are under active development. With these techniques, drastic enhancement of the corrosion resistance and minimization of coating material consumption can be acquired. ${ }^{6}$ First application of aluminum PVD on the $300 \mathrm{~mm}$ wide steel substrate was conducted in early 1960s in the US. And the first commercial continuous vapor deposition line, in which aluminum deposited steel strips with a width of $600 \mathrm{~mm}$, was built in Germany. Recently, European companies are producing zinc or zinc-magnesium alloy coated sheet steels for automotive and home appliances since 2005 and are considering the facilities to produce zinc-magnesium double layer coating by additional magnesium vapor deposition on the galvanized sheet steels.

In order to improve the corrosion resistance of automotive steel, new coating materials containing corrosion resistant elements are being developed. Magnesium is shown to be most effective in enhancement of the corrosion resistance by increasing the ratio of the aluminum rich phase,

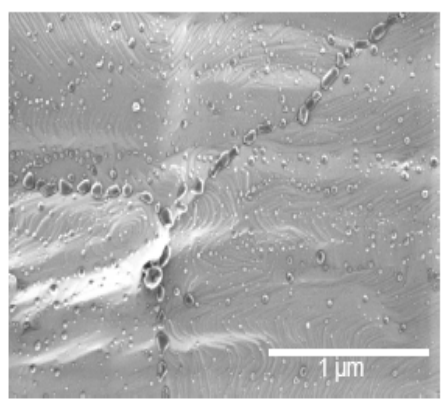

(a)

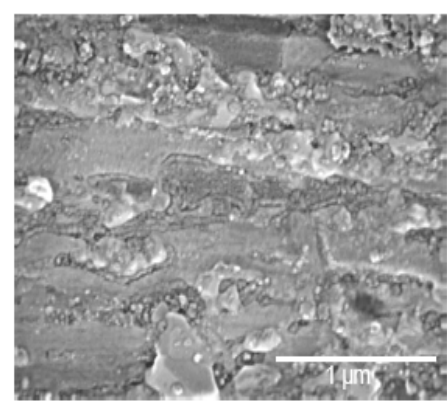

(b)

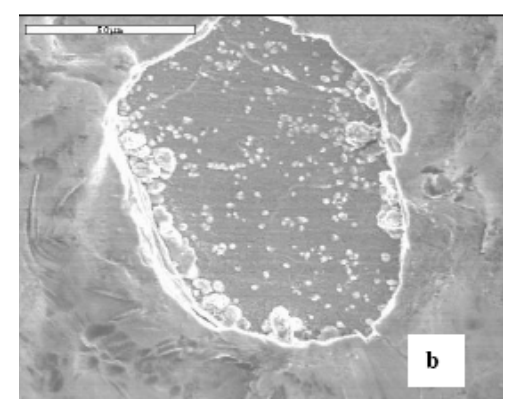

(c)

Fig. 5. Surface condition of (a) IF steel, (b) high strength steel after annealing and (c) bare spot after hot dip galvanizing.
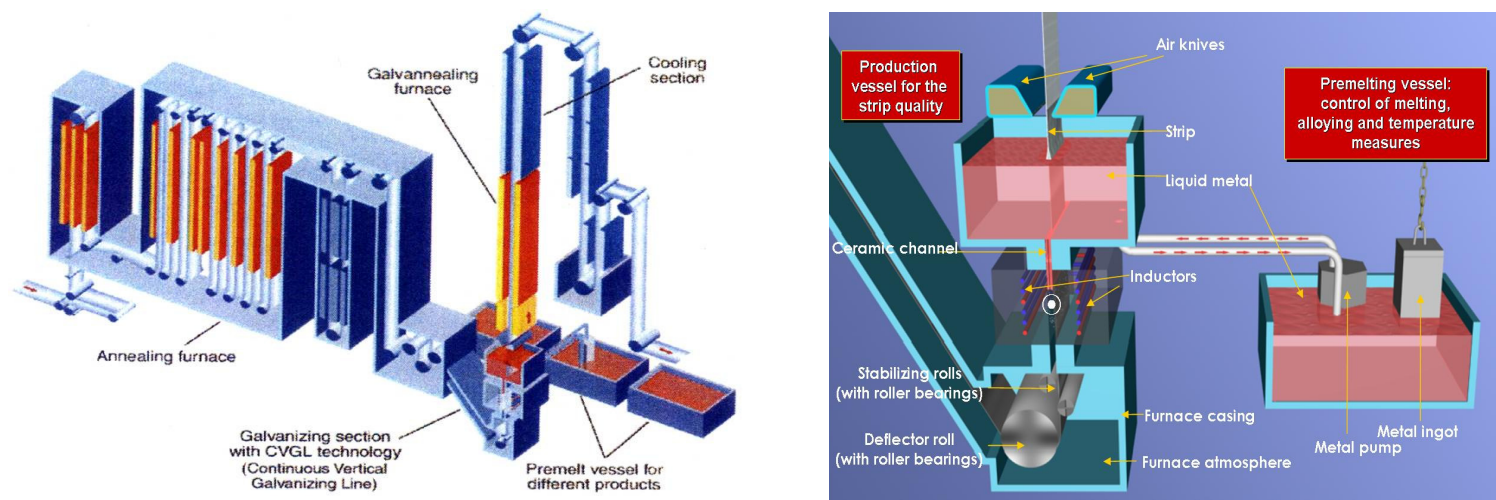

Fig. 6. Schematic diagram of CVGL technology. 
and forming a protective compact layer on the coating surface. $^{14), 15)}$ On the basis of this concept, several kinds of zinc-aluminum-magnesium alloy coatings such as ZAM $(\mathrm{Zn}-6 \% \mathrm{Al}-3 \% \mathrm{Mg})$ by Nisshin Steel and DYMAZINC (Zn-11\%Al-3\%Mg-0.2\%Si) by NSC are developed.

\subsection{New hot-dip coating technology for higher surface quality and productivity}

Lately, new hot-dip coating technology with higher surface quality and productivity, distinct from conventional hot-dip coating technology is under developing. Fig. 6 shows the schematic diagram of hot-dip facilities adopting levitation zinc pot named CVGL(Continuous Vertical Galvanizing Line). Applied Lorentz Force into molten metal can counterbalance the gravitational force, thus molten metal can levitate inside of the ceramic channel below the coating pot. Advantages of CVGL technology are as follows. First, better surface quality of coated steel can be acquired by preventing the sink roll groove mark and dross insertion between strip and sink roll. Second, higher production speed can be obtained compared to conventional hot dip coating because there is no mechanical interference in molten bath. Third, continuous production is possible without the loss of time and cost in changing sink roll periodically.

\section{Lightweight automotive part technologies}

Improved fuel efficiency, passenger safety are of great importance in the automotive industry. To meet these demands, cooperative researches are on the progress between carmaking and steelmaking companies. New technologies such as hydroforming, TWB(Tailor Welded Blank) and hot stamping have been developed, also convergence technologies such as TWC(Tailor Welded Coil), TRB(Tailor Rolled Blank) and hot stamping combined with TWB are actively being investigated.

Hydroforming technology utilizes steel pipe or sheet steel as a raw material. After bending and preforming, hydraulic pressure is applied into the cavity to form the final shape according to the mold design. Tube hydroforming technique applies hydraulic pressure into steel pipe to produce the final shape. Sheet hydroforming applies hydraulic pressure between sheet steel and lower die, and then punch press to get the product. Fig. 7 shows the schematic diagram of hydroforming process.

TWB technology is the process by which sheet steels having different thickness are laser-welded together to form single blank. Using this process, approximately $10 \%$ of weight saving and increased crashworthiness can be achieved.

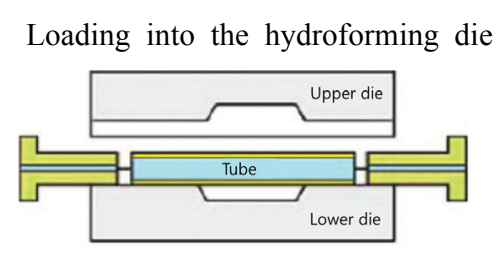

Closing of the hydroforming die

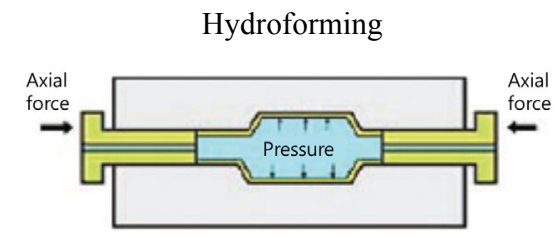

(a) Tube hydroforming
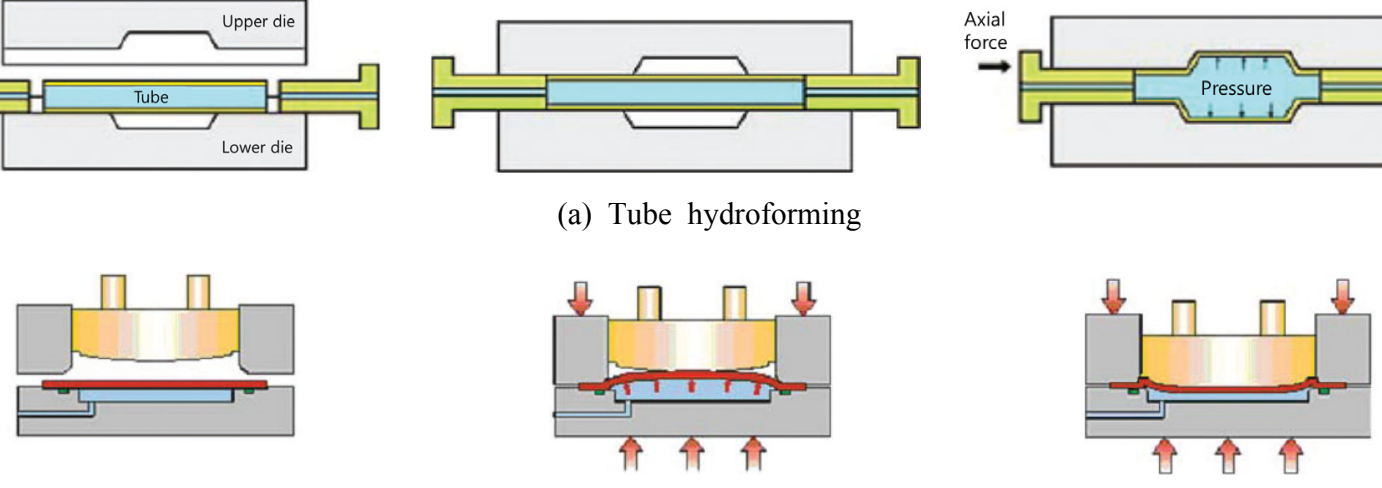

(b) Sheet hydroforming

Fig. 7. Schematic diagram of Hydroforming process.
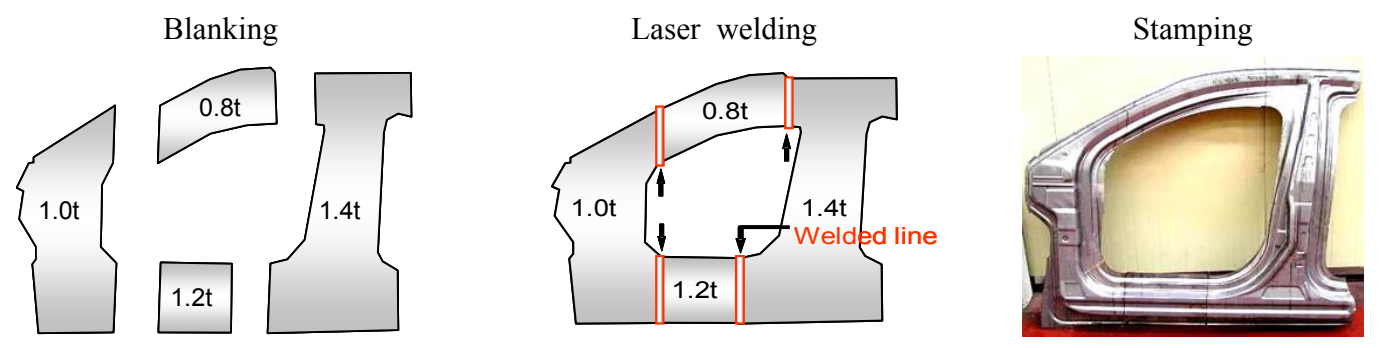

Fig. 8. Schematic diagram of TWB process. 
Hot stamping technology includes, heating of sheet steels with high hardenability up to above austenite transformation temperature, pressing and quenching by the press die cooled by circulating water inside the die to get high strength parts with $1500 \mathrm{MPa}$ grade tensile strength. By high temperature forming at above $900{ }^{\circ} \mathrm{C}$ and rapid quenching to ambient temperature, good formability and sufficient hardenability can be obtained.

Indirect hot stamping is the kind of hot stamping technology. Sheet steels are preformed up to $90 \sim 95 \%$ of final shape at room temperature, then hot stamped for final forming. With this technique, parts with complex shape can be produced and laser cutting process after pressing can be eliminated. Fig. 10 shows the schematic diagram of indirect hot stamping.
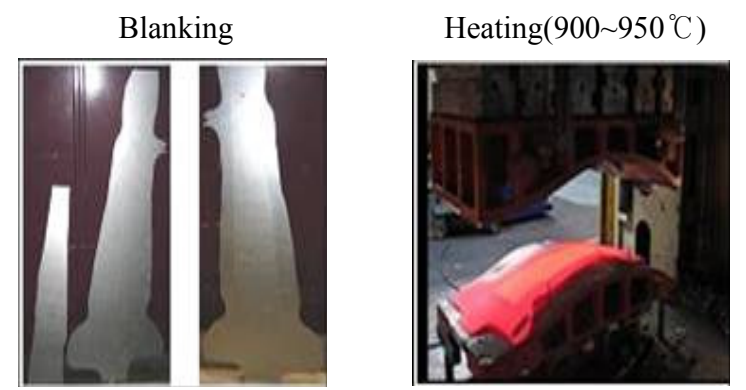

Recently, convergence technologies for satisfying both weight reduction and safety are being developed. Hot stamping combined with TWB can reduce the loss of sheet steel during blank production, resulting in the enhancement of production yield rate. Moreover, this technology can get different hardening effect according to the segment of a single part, thus maximum energy absorption in the crashed area and improved passenger safety can be acquired. Fig. 11 shows the schematic diagram of Hot stamping+TWB process.

Convergence technologies such as TRB(Tailor Rolled Blank), TWC(Tailor Welded Coil) and TWT(Tailor Welded Tube) can reduce the number of overall automotive parts and can simplify the assembly process. TRB technique includes controlling the gap between the cold rolling work

Fig. 9. Hot Stamping process.
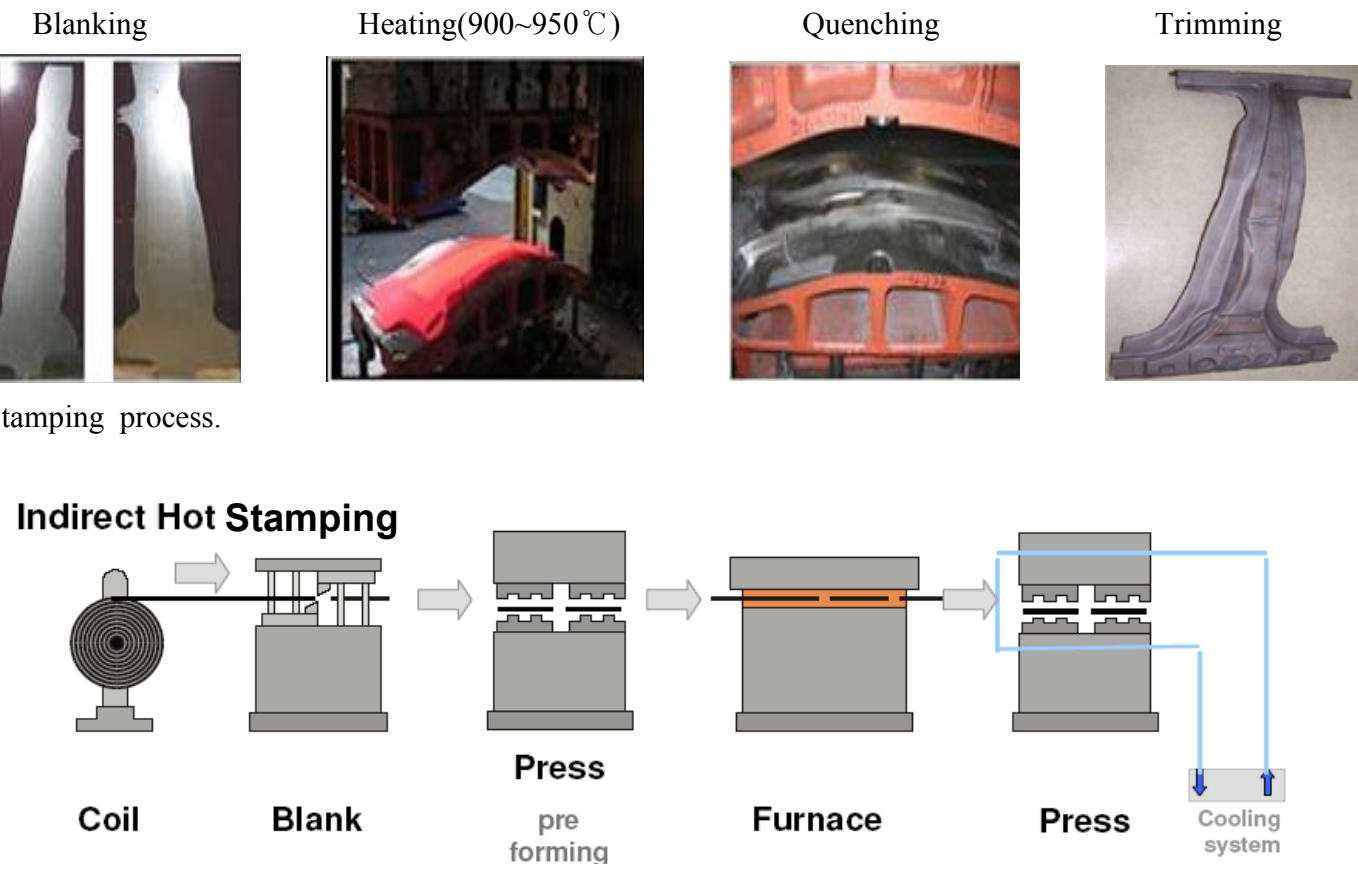

Fig. 10. Schematic diagram of Indirect Hot Stamping.

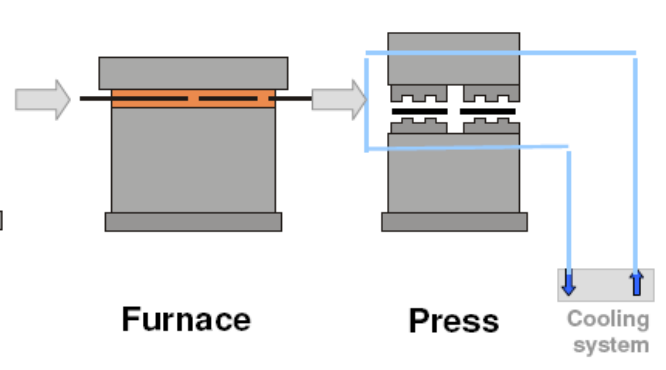

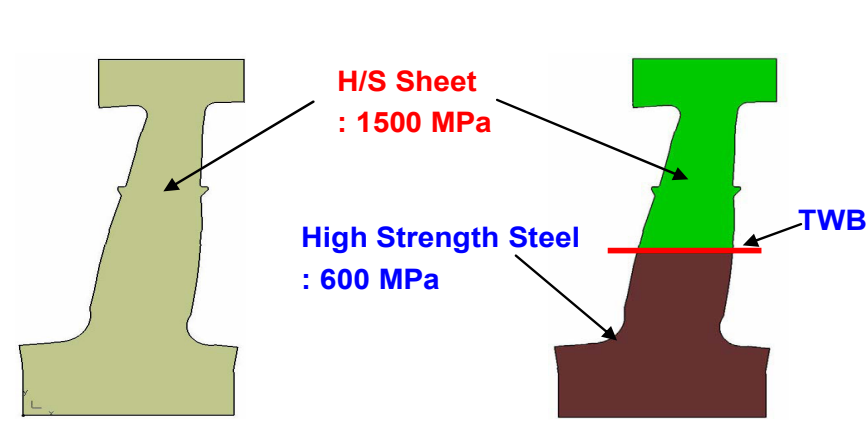

(a)

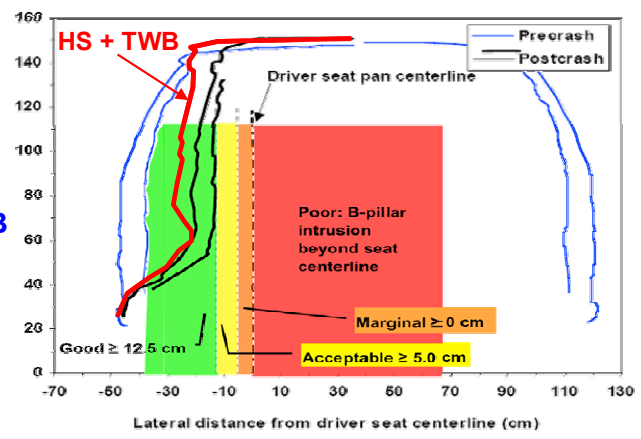

(b)

Fig. 11. (a)Schematic diagram of Hot Stamping+TWB convergence process (b)Enhancement of crashworthiness. 


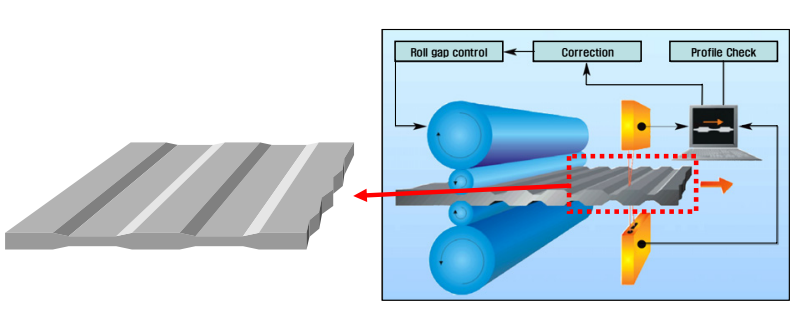

(a)

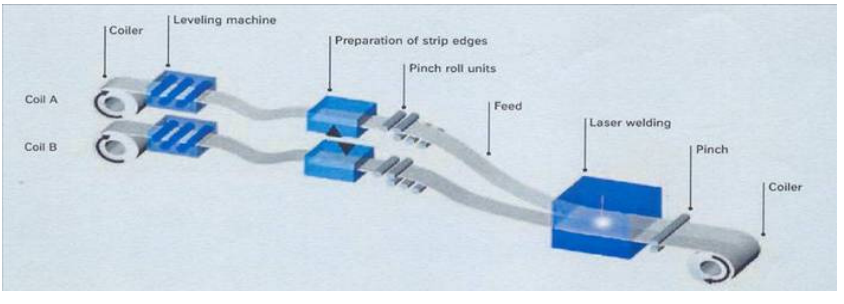

(b)

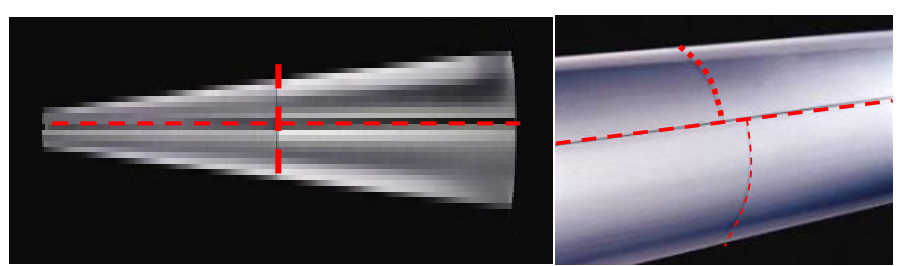

(c)

Fig. 12. Convergence technologies for lightweight car body

(a) TRB, (b) TWC, (c) TWT.

rolls to produce steel strip with variable thickness. European steelmaking companies developed TWC technique which joins more than two coils with different strength and thickness by laser welding to produce single coil. Automotive parts such as door inner, pillar and seat runner are under development with TWC strip. TWT is the technique to produce steel tube by laser welding after forming blank. This technique is advantageous to produce the tubes with ultra high strength or coated(galvanized, galvannealed) steel product having different strength and shape. Fig. 12 illustrates the convergence technologies mentioned above.

\section{Summary}

Advanced high strength steels are increasingly being used for carbody lightening and crashworthness in automotive industry.

It is obviously expected that various kinds of advanced high strength steels including HSS with TS above 490 $\mathrm{MPa}$ for outer panel, from $590 \mathrm{MPa}$ to $780 \mathrm{MPa}$ for member parts, and from $1180 \mathrm{MPa}$ to 1470 for bumper or reinforcement parts are aggressively adopted.

New coating materials including $\mathrm{Mg}$ containing $\mathrm{Zn}-\mathrm{Al}$ Alloy are being developed to enhance corrosion resistance. Several kinds of new process and application technologies such as TWB, Hydroforming and Hot stamping, fur- thermore convergence technologies including TRB, TWC, TWT are being introduced for process simplification and cost reduction. Hereafter needs for new materials and application processes are expected to be more strengthened in the future.

\section{References}

1. K-P. Imlau and T. Heller, Steel Res. Int., 78, 180 (2007).

2. M. Babbit, Steel Res. Int., 77, 620 (2006).

3. ULSAB-AVC Program, Technical Transfer Dispatch \#6: ULSAB-AVC Body Structures Materials, ULSAB-AVC Consortium, May 26, p. 2 (2001).

4. IISI, Ultra Light Steel Auto Body Advanced Vehicle Concepts (ULSAB-AVC) Overview Report (2002).

5. Bertram Ehrhardt et al, AHSSS Proceedings, Colorado, USA, p. 39 (2004).

6. Bull. of ISIJ, 11, 766 (2006).

7. Rolf Bode et al, Proceedings of Galvatech 2004, p. 107, Chicago, USA, AIST (2004).

8. A. Komatsu et al, Nisshin Seiko Giho, 77, 1 (1998).

9. Y. Hashimoto et al, Tetsu-to-Hagane, 89, 31 (2003).

10. Ch. Schwerdt et al, Proceedings of Galvatech 2004, p. 620, Chicago, USA (2004).

11. H. Shindo et al, Proceedings of Galvatech 1998, p. 433, Chiba, Japan, ISIJ (1998).

12. T. Tsujimura et al, Proceedings of Galvatech 2001, p. 145, Brussels, Belgium, CRM (2001). 